\title{
Thymosin $\beta 4$ promotes glucose-impaired endothelial progenitor cell function via Akt/endothelial nitric oxide synthesis signaling pathway
}

\author{
FUYU QIU*, JIALE SONG ${ }^{*}$, XUKUN BI, MEIHUI WANG, YANBO ZHAO and GUOSHENG FU \\ Department of Cardiology, Sir Run Run Shaw Hospital, College of Medicine, \\ Zhejiang University, Hangzhou, Zhejiang 310016, P.R. China
}

Received August 15, 2015; Accepted August 25, 2016

DOI: $10.3892 /$ etm.2018.6593

\begin{abstract}
Circulating endothelial progenitor cells (EPCs) are a subtype of hematopoietic stem cells, which can differentiate into endothelial cells and restore endothelial function. However, high glucose decreases the number and impairs the function of EPCs. A previous study showed that thymosin $\beta 4$ (T $\beta 4$ ), a pleiotropic peptide beneficial for multiple functions of various types of cells, could promote EPC migration and dose-dependently upregulate the phosphorylation of Akt and endothelial nitric oxide synthesis signaling (eNOS). In present study, the hypothesis that $\mathrm{T} \beta 4$ can improve glucose-suppressed EPC functions via the Akt/eNOS signaling pathway and restores the production of nitric oxide (NO) is investigated. EPCs were isolated from the peripheral blood of healthy volunteers and formed a cobblestone shape after 3-4 weeks of cultivation. Then, EPCs were treated with high concentrations of glucose $(25 \mathrm{mM})$ for 4 days and administrated with $\mathrm{T} \beta 4$ for further study. Transwell migration and tube formation assays were performed to access the migratory and angiogenic ability of EPCs. In addition, the quantity of Akt, eNOS and the concentration of nitric oxide (NO) was investigated. Functional studies showed that high concentrations of glucose significantly suppressed EPC function, while this adverse effect was reversed by the administration of $\mathrm{T} \beta 4$. In addition, Akt small interfering (si)RNA and eNOS siRNA were demonstrated to reduce the protective effect of $\mathrm{T} \beta 4$ against glucose-impaired EPC functions. These findings suggest that $\mathrm{T} \beta 4$ improves
\end{abstract}

Correspondence to: Dr Guosheng Fu or Mr Fuyu Qiu, Department of Cardiology, Sir Run Run Shaw Hospital, College of Medicine, Zhejiang University, 3 East Qingchun Road, Hangzhou, Zhejiang 310016, P.R. China

E-mail: fugs@medmail.com.cn

${ }^{*}$ Contributed equally

Key words: endothelial progenitor cells, thymosin $\beta 4$, hyperglycemia, migration, angiogenesis glucose-impaired EPC functions via the Akt/eNOS signaling pathway.

\section{Introduction}

Diabetes mellitus is associated with an increased risk of ischemic cardiovascular diseases, including coronary heart disease and stroke, which seriously jeopardize human health (1). The mechanism of this association is complicated. Vascular injury, occlusion or degradation caused by endothelial dysfunction in hyperglycemia may serve an important role. Accumulating evidence suggests that circulating endothelial progenitor cells (EPCs) can promote reendothelialization and restore endothelial function $(2,3)$. Nevertheless, the number of EPCs is decreased in type I and type II diabetes $(4,5)$. In addition, EPC functions, such as proliferation, migration and angiogenesis, are severely suppressed in diabetes $(6,7)$. Therefore, ameliorating the impaired functions of EPCs is urgent and critical for EPC-based cell therapy, particularly with regard to ischemic cardiovascular disease associated with diabetes.

Thymosin $\beta 4$ (T $\beta 4)$ is a pleiotropic peptide serving various roles in cell migration $(8,9)$, angiogenesis $(10)$, apoptosis (11) and inflammation (12). Recent studies have suggested that $\mathrm{T} \beta 4$ can exert cardiovascular protective effects by enhancing the proliferation, migration and angiogenesis of a variety of stem or progenitor cells $(9,13-15)$. Previous studies by the authors of the present study demonstrated that T $\beta 4$ could promote EPC migration, prevent EPCs from serum deprivation-induced apoptosis and reduce the senescence of EPCs in vitro $(11,16,17)$. However, whether T $\beta 4$ can improve glucose-impaired EPC function, and the underlying mechanism associated with this, remain unclear. In there present study, the effect of $\mathrm{T} \beta 4$ on glucose-impaired EPC function is investigated, and the potential signaling pathway involved is discussed.

\section{Materials and methods}

Cell culture. Mononuclear cells were isolated from the peripheral blood of healthy donors by density-gradient centrifugation using Ficoll separating solution (Cedarlane Laboratories, Ltd., Hornby, Canada). Then, $1 \times 10^{7}$ mononuclear cells were plated on fibronectin (Chemicon, Temecula, CA, USA)-coated plates 
and incubated with endothelial growth medium-2 (EGM-2 MV; Clonetics, Walkersville, MD, USA). After 3 days of culturing, non-adherent cells were removed by washing with phosphate buffered saline (PBS; 0.2 M, pH 7.4) and new medium was applied. A number of cells grew into EPCs which exhibited a 'cobblestone' shape after 3-4 weeks. The EPCs were detached by trypsin and collected for the following experiments.

EPC migration assay. EPC migration was assessed using a transwell migration assay (3422; Costar, Cambridge, MA, USA). A total of $5 \times 10^{4}$ cells were re-suspended in $100 \mu 1$ serum-free endothelial basal medium-2 (EBM-2; Clonetics) and placed in the upper chambers of 24-well transwell plates with $8 \mu \mathrm{m}$-pore membranes. Then, $600 \mu \mathrm{l}$ EGM-2 supplemented with $10 \%$ bovine serum albumin (Amresco LLC, Solon, $\mathrm{OH}, \mathrm{USA}$ ) was placed in lower chambers. After $6 \mathrm{~h}$ of incubation at $37^{\circ} \mathrm{C}$, the upper side of membrane was wiped gently with cotton swabs to remove the cells that had not migrated. The migrated cells were fixed in $4 \%$ paraformaldehyde and stained using 4'6-diamidino-2-phenylindole (Roche Applied Science, Indianapolis, IN, USA). Migrated cells were counted with a fluorescence microscope at $\times 400$ magnification and 5 random fields were picked for counting. The average cell number of these 5 fields was considered as the cell migration number for each group.

EPC tube formation assay. Tube formation was performed with Matrigel matrix basement membrane (BD Biosciences, Franklin Lakes, NJ, USA) to evaluate the ability of EPC angiogenesis. Matrigel solution was thawed at $4^{\circ} \mathrm{C}$ overnight, diluted with EBM-2 and added in a 96-well plate at $37^{\circ} \mathrm{C}$ for $1 \mathrm{~h}$ to solidify. EPCs were collected with trypsin and re-suspended with EGM-2 MV medium, then $2 \times 10^{4}$ EPCs were placed on the matrix for further incubation at $37^{\circ} \mathrm{C}$ for $6-8 \mathrm{~h}$. Tube formation was observed with a light microscope (magnification, $\mathrm{x} 100$ ) and 5 random fields were chosen for each assay. The average tube formation counted by branch point numbers was compared in different groups by Image Pro Plus version 6.0 (Media Cybernetics, Warrendale, PA, USA).

Small interfering RNA (siRNA) transfection. siRNA against Akt and eNOS were synthesized by GenePharma Co., Ltd. (Shanghai, China) and a nonsense sequence was designed as a negative control. The effective Akt siRNA sequence was as follows: Sense, 5'-GCACUUUCGGCAAGGUGAUTT-3' and antisense, 5'-AUCACCUUGCCGAAAGUGCTT-3'. The effective eNOS siRNA sequence was as follows: Sense, 5'-CAGUACUACAGCUCCAUUATT-3' and antisense, 5'-UAAUGGAGCUGUAGUACUGTT-3'. Then, $4 \times 10^{5}$ EPCs were placed in 6-well plates, and when cells reached 60-80\% confluence, they were transfected with Akt and eNOS siRNA and cultured for $24 \mathrm{~h}$, then incubated with a high concentration of glucose $(25 \mathrm{mM})$ for 4 days (except for the control group), and with or without T $\beta 4$ (ProSpec-Tany TechnoGene, Ltd., Rehovot, Israel) for the last $24 \mathrm{~h}$. The effectiveness of Akt and eNOS knock-down was determined by western blotting.

Western blots analysis and measurement of nitric oxide $(N O)$. Total protein from EPCs was extracted with radioimmunoprecipitation assay lysis buffer (Beyotime Institute of Biotechnology, Shanghai, China). Protein concentration was measured using a BCA assay kit (P0012; Beyotime Institute of Biotechnology). Equal quantities of protein $(20 \mu \mathrm{g})$ were run on a $10 \%$ tris-glycine gradient gel, then transferred to polyvinylidene difluoride membranes and blocked with $5 \%$ non-fat milk in Tris-buffered solution containing $0.1 \%$ Tween 20 (TBST) for $1 \mathrm{~h}$ at $25^{\circ} \mathrm{C}$. Membranes were then incubated with primary antibodies at $4^{\circ} \mathrm{C}$ overnight and with secondary antibodies at room temperature for $1-2 \mathrm{~h}$. Membranes were washed three times with TBST for $15 \mathrm{~min}$ before and after the incubations. Finally, proteins were visualized with enhanced chemiluminescence reagent (Lianke Biotechnology, Hangzhou, China) and exposed to Image Quant LAS-4000 (Fujifilm, Tokyo, Japan). Grayscale of the bands were measured by Multi-Gauge 3.0 image analysis software (Fujifilm). Antibodies including anti-phospho-Akt-Ser ${ }^{473}(1: 1,000 ; 3787)$, anti-Akt (1:1,000; 9272), anti-phospho-endothelial nitric oxide synthase (eNOS)-Ser ${ }^{1177}(1: 1,000 ; 9571)$, anti-eNOS (1:1,000; 9572 ) and horseradish peroxidase-conjugated goat anti-rabbit $\operatorname{IgG}(1: 5,000 ; 7074)$ were purchased from Cell Signaling Technology, Inc. (Beverly, MA, USA). After incubation of EPCs with or without $\mathrm{T} \beta 4$ in glucose for 4 days, the conditioned medium was examined for NO using Griess regent (Beyotime Institute of Biotechnology).

Statistical analysis. All experiments were performed for at least three individual experiments. Statistical analysis was performed using SPSS version 19.0 software (IBM SPSS, Amronk, NY, USA), using one-way analysis of variance nad post-hoc least standard difference analysis. Results are presented as the mean \pm standard error. $\mathrm{P}<0.05$ was considered to indicate a statistically significant difference.

\section{Results}

TR4 ameliorates glucose-impaired EPC migration and angiogenesis. It was investigated whether the administration of T $\beta 4$ could improve glucose-impaired EPC functions. As shown in Fig. 1A, incubation of EPCs with medium with a high concentration of glucose $(25 \mathrm{mM})$ for 4 days could significantly suppress EPC migration $(\mathrm{P}<0.01$ vs. the control group). However, treatment with $\mathrm{T} \beta 4$ for $24 \mathrm{~h}$ after the exposure of EPCs to high glucose conditions could improve glucose-suppressed EPC migration in a concentration-dependent manner; the maximal pro-migratory dose was observed at $1,000 \mathrm{ng} / \mathrm{ml}(\mathrm{P}<0.01$ vs. the glucose group; Fig. 1A). In addition, high concentrations of glucose significantly impaired EPC tube formation ability $(\mathrm{P}<0.01 \mathrm{vs}$. the control group; Fig. 1B). Treatment with T $\beta 4$ for $24 \mathrm{~h}$ after glucose exposure ameliorated glucose-suppressed EPC tube formation ability in a concentration-dependent manner; the maximal pro-angiogenic dose was observed at $1,000 \mathrm{ng} / \mathrm{ml}$ $(\mathrm{P}<0.01$ vs. the glucose group; Fig. 1B).

T $\beta 4$ restores glucose-inhibited AktleNOS phosphorylation and NO production. High concentrations of glucose can inhibit Akt and eNOS activation and reduce NO production in EPCs (18). A previous study indicated that T $\beta 4$ may activate the phosphorylation of Akt and eNOS $(16,17)$. Therefore, the 
A
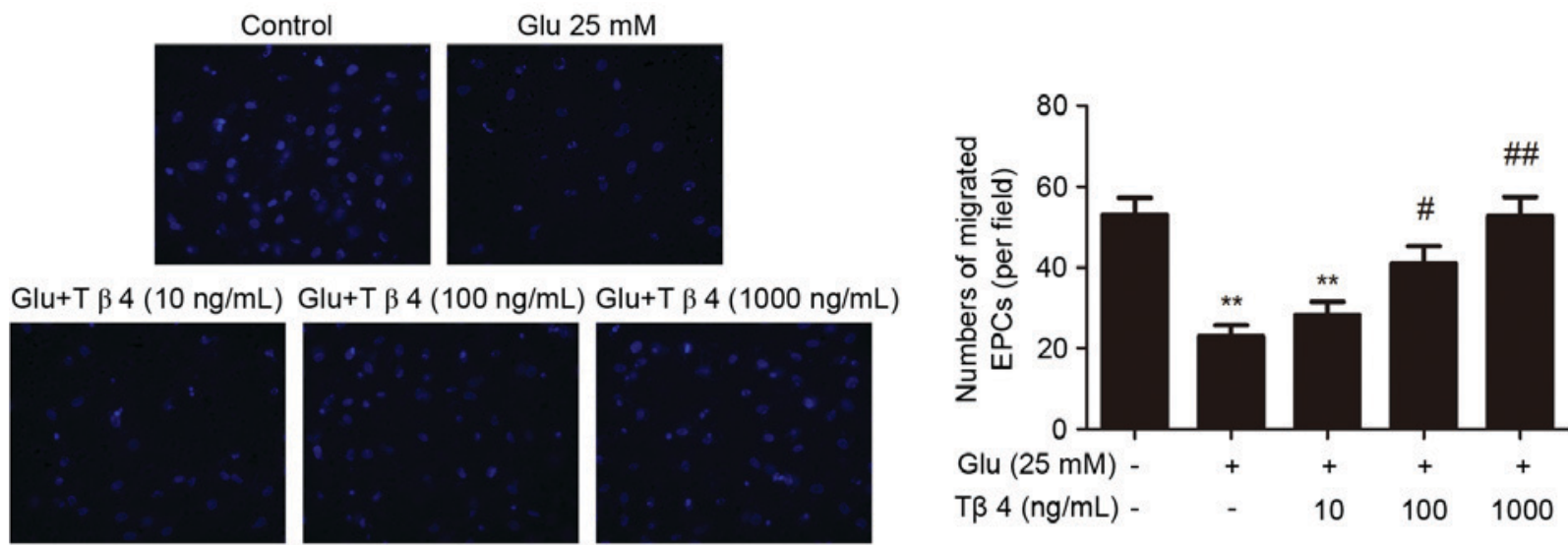

B
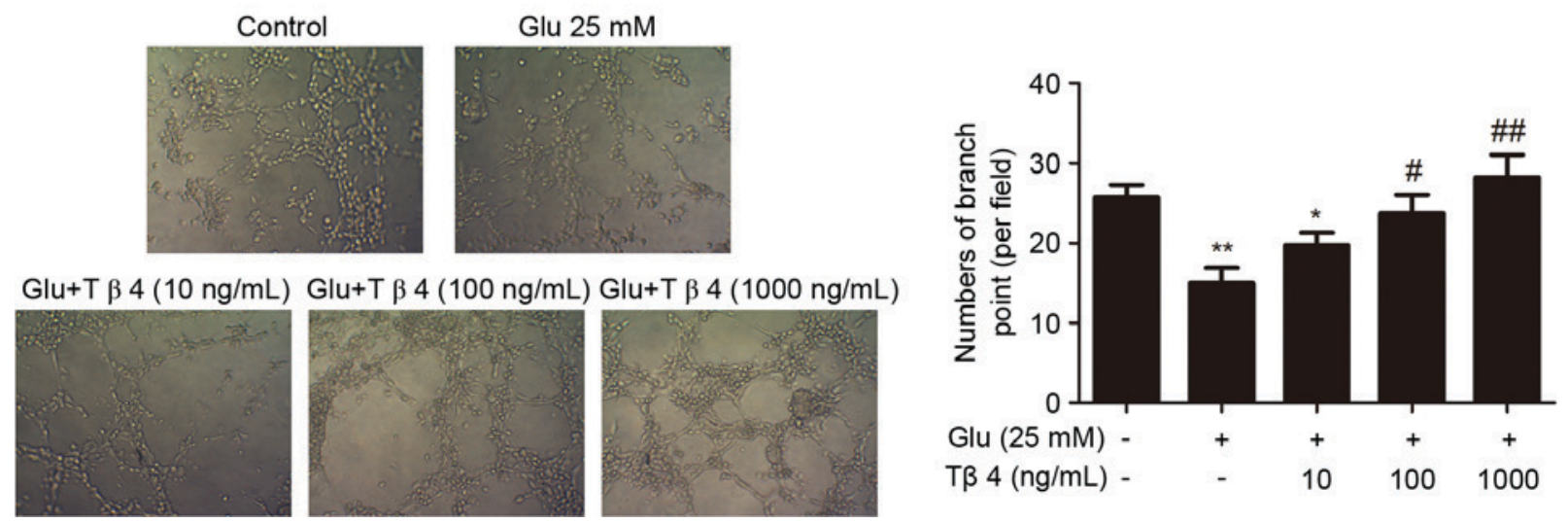

Figure 1. T $\beta 4$ restores glucose-suppressed EPC migration and angiogenesis. Following treatment of EPCs with various concentrations of T $\beta 4$ (10 ng/ml, $100 \mathrm{ng} / \mathrm{ml}$ and $1000 \mathrm{ng} / \mathrm{ml}$ ) for $24 \mathrm{~h}$, cultured EPCs were evaluated by using functional assays following incubation with high glucose medium for 4 days. (A) A transwell migration assay was used to assess the effect of T $\beta 4$ on EPC migration in high concentrations of Glu. 4'6-diamidino-2-phenylindole staining was performed to determine the number of migrated EPCs (magnification, $\mathrm{x} 400$ ). (B) An in vitro tube formation assay was performed to investigate the effect of T $\beta 4$ on EPC neovascularization in high concentrations of Glu. Number of branch points was counted to evaluate the effect of T $\beta 4$ on EPC angiogenesis in high-glucose medium. $(\mathrm{n}=4)$. ${ }^{*} \mathrm{P}<0.05$ and ${ }^{* *} \mathrm{P}<0.01$ vs. the control; ${ }^{*} \mathrm{P}<0.05$ and ${ }^{\# \#} \mathrm{P}<0.01$ vs. the high-glucose group. T $\beta 4$, thymosin $\beta 4$; EPC, endothelial progenitor cell; Glu, glucose.

effects of T $\beta 4$ on glucose-exposed EPCs were investigated in order to determine whether $\mathrm{T} \beta 4$ can restore glucose-inhibited Akt and eNOS phosphorylation in EPCs. As shown in Fig. 2A, high concentrations of glucose $(25 \mathrm{mM})$ dramatically down-regulated the phosphorylation of Akt at $\mathrm{Ser}^{473}$ and eNOS at Ser ${ }^{1177}$ in EPCs, while there was no significant change in total Akt and eNOS expression. The inhibition of eNOS phosphorylation led to reduced NO production of EPCs (Fig. 2B). However, administration of T $\beta 4$ in the glucose medium for $24 \mathrm{~h}$ concentration-dependently upregulated the phosphorylation of Akt and eNOS, and augmented NO production (Fig. 2).

Akt/eNOS signaling pathway is involved in the amelioration of glucose-impaired EPC functions by T $\beta 4$. To identify the role of the Akt/eNOS signaling pathway in the beneficial effect of T $\beta 4$ on glucose-impaired EPC functions, EPCs were transfected with Akt siRNA and eNOS siRNA to decrease Akt and eNOS activity, respectively. As shown in Fig. 3, administration of Akt and eNOS siRNA (50 nM) markedly inhibited the benefit of $\mathrm{T} \beta 4$ in improving EPC migration and tube formation, suggesting that the Akt/eNOS pathway accounts for T $\beta 4$-induced improvement of glucose-suppressed EPC functions.

\section{Discussion}

Previous studies performed by the authors of the present study have demonstrated that T $\beta 4$ may exert an important role in enhancing EPC functions, including promoting migration, inhibiting apoptosis and senescence $(11,16,17)$. However, the capacity of $\mathrm{T} \beta 4$ to reverse impaired EPC functions in some pathological conditions remains unclear. The present study demonstrated that $\mathrm{T} \beta 4$ could reverse glucose-impaired EPC functions in a dose-dependent manner and elucidated that the beneficial effect of T $\beta 4$ may be associated with the Akt/eNOS signaling pathway and NO-related mechanisms.

At present, diabetes mellitus has become a common diseases worldwide, which is associated with poor clinical outcomes and premature morality due to its cardiovascular complications $(19,20)$. Several studies have suggested that the imbalance between endothelial injury and repair is a key process of diabetes-associated cardiovascular complications $(21,22)$. Endothelial function is impaired in diabetes and the complication of vascular occlusion in diabetic patients has been attributed to compromised collateral vessel formation due to diminished capacity of mature endothelial cells (1). EPCs have proliferating potential, differentiating into endothelial cells and promoting regeneration and angiogenesis of 
A

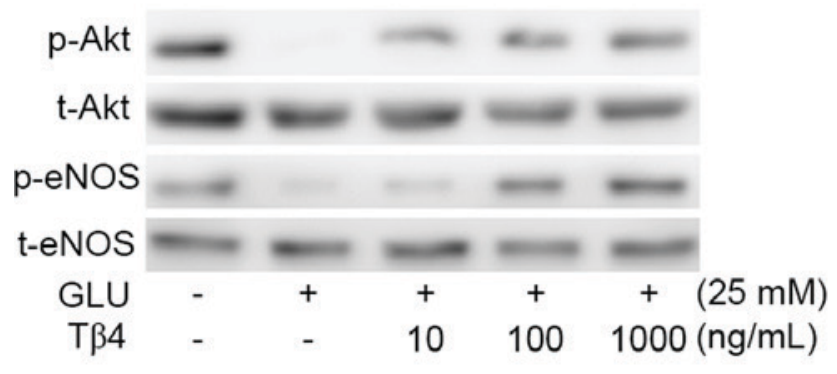

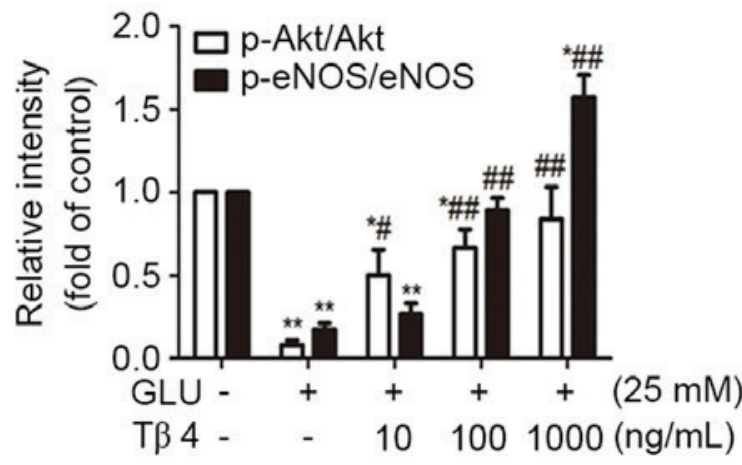

B

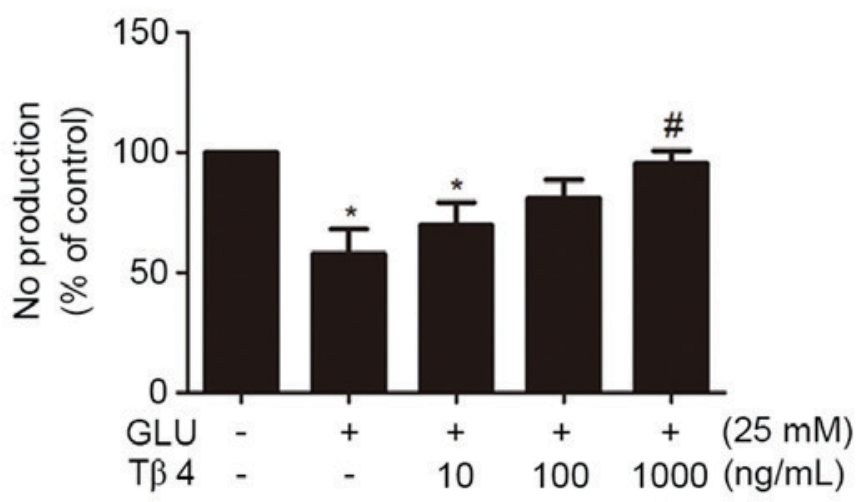

Figure 2. T $\beta 4$ recovers glucose-inhibited EPC Akt/eNOS activation and NO production. (A) Effects of T $\beta 4$ on the expression and phosphorylation of Akt and eNOS, examined in EPCs by western blotting. (B) Nitrate production was measured by Griess reagent. ( $\mathrm{n}=4$ ). ${ }^{*} \mathrm{P}<0.05$ and ${ }^{* * *} \mathrm{P}<0.01$ vs. the control group; ${ }^{\#} \mathrm{P}<0.05$ and ${ }^{\# \#} \mathrm{P}<0.01$ vs. the high-glucose group. T $\beta 4$, thymosin $\beta 4$; EPC, endothelial progenitor cell; Glu, glucose; NO, nitric oxide; eNOS, endothelial NO synthesis; p-eNOS, phosphorylated eNOS t-eNOS, total eNOS; p-Akt, phosphorylated-Akt.

endothelial cells, which serves an important role in maintaining endothelial function and integrity, as well as post-natal neovascularization (23). Interestingly, emerging evidence has showed that post-natal neovascularization in adults may be involved with EPCs directly (24). Hence, EPCs could be a potential method for cardiovascular therapy. However, it has been revealed that the number and function of EPCs may be reduced by several cardiovascular risk factors, such as hypertension, hyperglycemia and hypercholesterolemia (25). Reduced numbers and suppressed function of EPCs can be associated with endothelial dysfunction, impaired angiogenesis and decreased compensational collateralization in occlusive vascular diseases (26). Type I and type II diabetes are both associated with decreased numbers and impaired function of EPCs. Therefore, strategies to improve the suppressed functions of EPCs is critical and beneficial for EPC-based cell therapy, particularly in treating diabetic patients.

In our present study, the functions of circulating EPCs is suppressed in high concentrations of glucose, and $T \beta 4$ was demonstrated to reverse the dysfunction of EPCs. T $\beta 4$ is a polypeptide originally isolated from calf thymus (27). Previous studies have observed that $\mathrm{T} \beta 4$ can modulate various physiological and pathological process, such as tissue development, wound healing, cell survival and vessel formation $(10,28-30)$. Previous studies by the authors of the present study have demonstrated that $\mathrm{T} \beta 4$ was able to enhance EPC migration, inhibit EPC apoptosis and senescence in vitro $(11,16)$. In addition, $\mathrm{T} \beta 4$ has been reported to enhance the angiogenesis of endothelial cells (31). Furthermore, $T \beta 4$ exerts excellent therapeutic effects against glucose damage. T $\beta 4$ is able to abolish glucose-suppressed capillary-like tube formation of endothelial cells and promote the recovery of neurological function in diabetic peripheral neuropathy (32). Kim and Kwon found that $\mathrm{T} \beta 4$ could ameliorate glucose-injured high-glucose-injured human umbilical vein endothelial cell function through the insulin-like growth factor-1 signaling pathway (33). According to the evidence above, the present study further revealed the beneficial effects of T $\beta 4$ on human EPCs in high concentrations of glucose, which may provide novel insights into its potential application for cardiovascular protection and therapy in clinical cases.

The Akt/eNOS signaling pathway has been reported to be a critical pathway that regulates cell migration and angiogenesis (34). As for EPCs, previous research has demonstrated that exercise and some medications, such as statins, could increase EPC number, proliferation and migration through the activation of the Akt protein (35). The stimulation of Akt protein kinase can further activate eNOS (36), which is essential and pivotal for the mobilization of stem and progenitor cells (37). A number of studies documented that hyperglycemia could affect various functions of different kinds of cells through the Akt/eNOS signaling pathway. Sun et al (38) identified that vaspin, a type of adipose factor, could alleviate EPC dysfunction caused by high concentrations of glucose via the PI3K/Akt/eNOS signaling pathway. Chen et al (18) indicated that high concentrations of glucose impaired EPC proliferation, migration and angiogenesis by down-regulating the phosphorylation Akt and eNOS, and NO production (18). The authors of the present study have previously revealed that $\mathrm{T} \beta 4$ promotes EPC migration and inhibits EPC apoptosis 
A
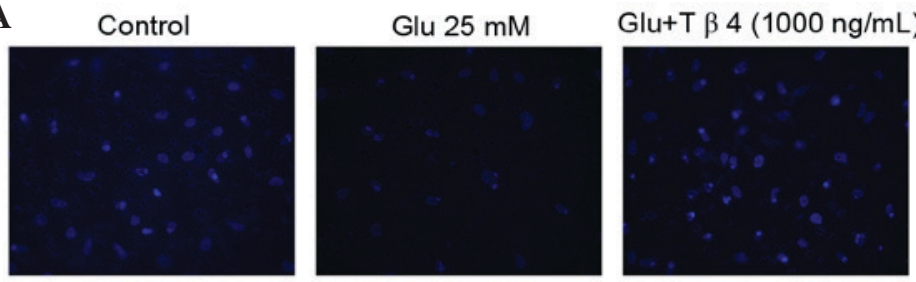

Glu+T $\beta$ 4+scramble
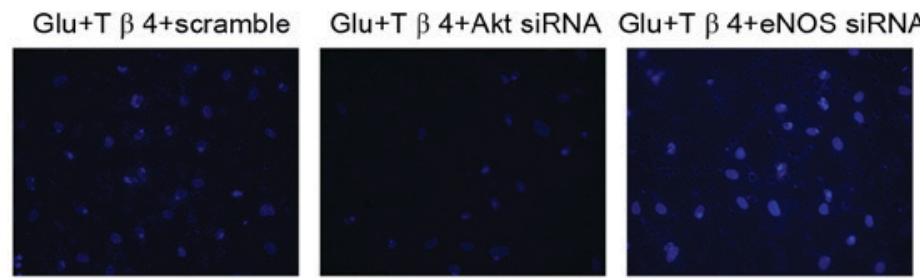

$\mathbf{B}$
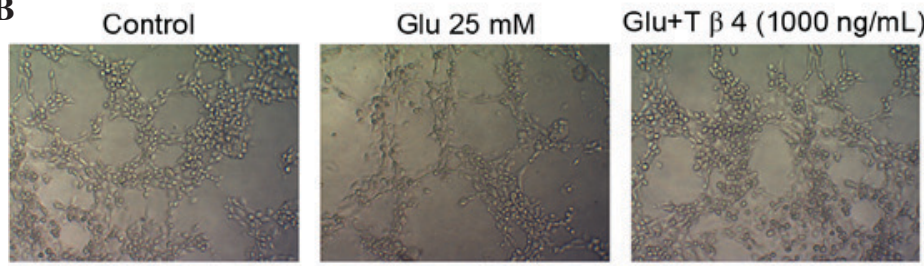

Glu+T $\beta$ 4+scramble
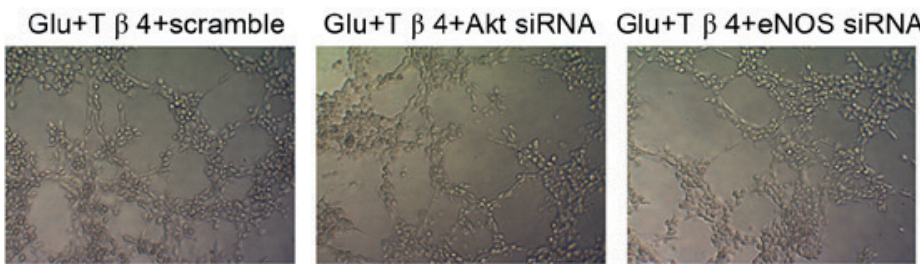

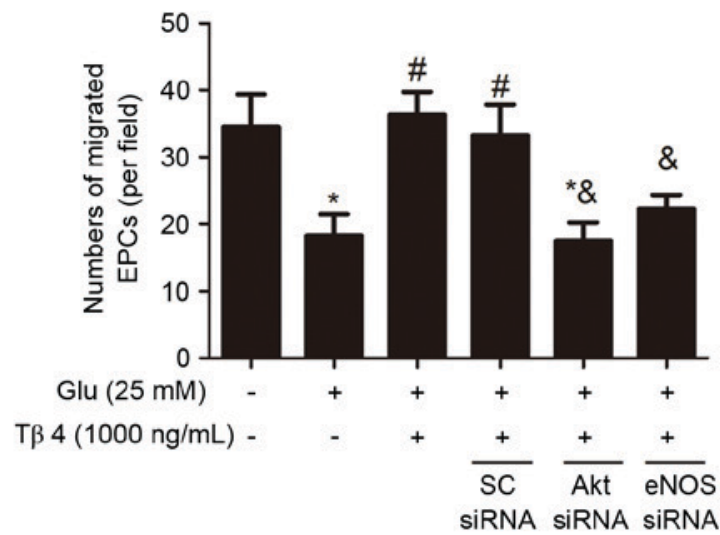

Figure 3. T $\beta 4$ improves glucose-impaired EPC functions via the Akt/eNOS signaling pathway. (A) T $\beta 4$ (1000 ng/ml) was administrated to EPCs 4 days after incubation with high concentrations of glucose. EPCs were pretreated with or without Akt and eNOS siRNA (50 nM) $24 \mathrm{~h}$ prior to the administration of T 34 (magnification, $\mathrm{x} 400$ ). (B) An in vitro angiogenesis assay was performed to determine the effect of T $\beta 4$ on EPC angiogenesis in high concentrations of glucose following the ablation of Akt and eNOS activity by Akt and eNOS siRNA. ( $\mathrm{n}=4$; magnification, $\mathrm{x} 100)$. ${ }^{*} \mathrm{P}<0.05$ and ${ }^{* *} \mathrm{P}<0.01$ vs. the control group; ${ }^{\#} \mathrm{P}<0.05$ and ${ }^{\# \#} \mathrm{P}<0.01$ vs. the high-glucose group; ${ }^{\&} \mathrm{P}<0.05$ vs. the high-glucose $+\mathrm{T} \beta 4$ group. T $\beta 4$, thymosin $\beta 4$; EPC, endothelial progenitor cell; Glu, glucose; eNOS, endothelial NO synthesis; SC, scramble; siRNA, small interfering RNA.

through the PI3K/Akt/eNOS signaling pathway $(11,16)$, therefore, it was postulated that this pathway may account for the T $\beta 4$-mediated improvement of glucose-suppressed EPC functions.

In present study, it was demonstrated that treatment with $\mathrm{T} \beta 4$ could provoke Akt and eNOS activity, and enhance the migration and tube formation of EPCs in high concentrations of glucose. These beneficial effects were blocked by the siRNA of Akt and eNOS. These findings suggest that T $\beta 4$ can ameliorate glucose-impaired EPC functions through the Akt/eNOS signaling pathway. According the findings above, T $\beta 4$ may be beneficial for maintaining EPC functions in high concentrations of glucose, which is helpful for understanding the therapeutic potential of $\mathrm{T} \beta 4$ for patients with diabetes and cardiovascular complications.

\section{Acknowledgements}

The present study was supported by the Special Major Projects of Zhejiang Province (grant no. 2010C13027) and the National Natural Sciences Foundation of China (grant nos. 81200112 and 81200114).

\section{References}

1. Abaci A, Oğuzhan A, Kahraman S, Eryol NK, Unal S, Arinç H and Ergin A: Effect of diabetes mellitus on formation of coronary collateral vessels. Circulation 99: 2239-2242, 1999.

2. Fujiyama S, Amano K, Uehira K, Yoshida M, Nishiwaki Y, Nozawa Y, Jin D, Takai S, Miyazaki M, Egashira K, et al: Bone marrow monocyte lineage cells adhere on injured endothelium in a monocyte chemoattractant protein-1-dependent manner and accelerate reendothelialization as endothelial progenitor cells. Circ Res 93: 980-989, 2003.

3. Werner N, Priller J, Laufs U, Endres M, Böhm M, Dirnagl U and Nickenig G: Bone marrow-derived progenitor cells modulate vascular reendothelialization and neointimal formation: Effect of 3-hydroxy-3-methylglutaryl coenzyme a reductase inhibition. Arterioscler Thromb Vasc Biol 22: $1567-1572,2002$

4. Loomans CJ, de Koning EJ, Staal FJ, Rookmaaker MB, Verseyden C, de Boer HC, Verhaar MC, Braam B, Rabelink TJ and van Zonneveld AJ: Endothelial progenitor cell dysfunction: A novel concept in the pathogenesis of vascular complications of type 1 diabetes. Diabetes 53: 195-199, 2004.

5. Fadini GP, Miorin M, Facco M, Bonamico S, Baesso I, Grego F, Menegolo M, de Kreutzenberg SV, Tiengo A, Agostini $C$ and Avogaro A: Circulating endothelial progenitor cells are reduced in peripheral vascular complications of type 2 diabetes mellitus. J Am Coll Cardiol 45: 1449-1457, 2005 . 
6. Ingram DA, Lien IZ, Mead LE, Estes M, Prater DN, Derr-Yellin E, DiMeglio LA and Haneline LS: In vitro hyperglycemia or a diabetic intrauterine environment reduces neonatal endothelial colony-forming cell numbers and function. Diabetes 57: 724-731, 2008.

7. Tepper OM, Galiano RD, Capla JM, Kalka C, Gagne PJ, Jacobowitz GR, Levine JP and Gurtner GC: Human endothelial progenitor cells from type II diabetics exhibit impaired proliferation, adhesion, and incorporation into vascular structures. Circulation 106: 2781-2786, 2002.

8. Malinda KM, Goldstein AL and Kleinman HK: Thymosin beta 4 stimulates directional migration of human umbilical vein endothelial cells. FASEB J 11: 474-481, 1997.

9. Smart N, Risebro CA, Melville AA, Moses K, Schwartz RJ Chien KR and Riley PR: Thymosin beta4 induces adult epicardial progenitor mobilization and neovascularization. Nature 445 177-182, 2007.

10. Grant DS, Rose W, Yaen C, Goldstein A, Martinez J and Kleinman H: Thymosin beta4 enhances endothelial cell differentiation and angiogenesis. Angiogenesis 3: 125-135, 1999.

11. Zhao Y, Qiu F, Xu S, Yu L and Fu G: Thymosin $\beta 4$ activates integrin-linked kinase and decreases endothelial progenitor cells apoptosis under serum deprivation. J Cell Physiol 226 : 2798-2806, 2011

12. Sosne G, Szliter EA, Barrett R, Kernacki KA, Kleinman H and Hazlett LD: Thymosin beta 4 promotes corneal wound healing and decreases inflammation in vivo following alkali injury. Exp Eye Res 74: 293-299, 2002.

13. Riley PR and Smart N: Thymosin beta4 induces epicardium-derived neovascularization in the adult heart. Biochem Soc Trans 37: 1218-1220, 2009.

14. Bock-Marquette I, Saxena A, White MD, Dimaio JM and Srivastava D: Thymosin beta4 activates integrin-linked kinase and promotes cardiac cell migration, survival and cardiac repair. Nature 432: 466-472, 2004

15. Bock-Marquette I, Shrivastava S, Pipes GC, Thatcher JE, Blystone A, Shelton JM, Galindo CL, Melegh B, Srivastava D Olson EN and DiMaio JM: Thymosin beta4 mediated PKC activation is essential to initiate the embryonic coronary developmental program and epicardial progenitor cell activation in adult mice in vivo. J Mol Cell Cardiol 46: 728-738, 2009.

16. Qiu FY, Song XX, Zheng H, Zhao YB and Fu GS: Thymosin beta4 induces endothelial progenitor cell migration via PI3K/Akt/eNOS signal transduction pathway. J Cardiovasc Pharmacol 53: 209-214, 2009.

17. Li J, Yu L, Zhao Y, Fu G and Zhou B: Thymosin $\beta 4$ reduces senescence of endothelial progenitor cells via the PI3K/Akt/eNOS signal transduction pathway. Mol Med Rep 7: 598-602, 2013

18. Chen YH, Lin SJ, Lin FY, Wu TC, Tsao CR, Huang PH, Liu PL, Chen YL and Chen JW: High glucose impairs early and late endothelial progenitor cells by modifying nitric oxide-related but not oxidative stress-mediated mechanisms. Diabetes 56 $1559-1568,2007$

19. Bitzur R: Diabetes and cardiovascular disease: When it comes to lipids, statins are all you need. Diabetes Care 34 (Suppl 2): S380-S382, 2011.

20. Bloomgarden ZT: Diabetes and cardiovascular disease. Diabetes care 34: e24-e30, 2011.

21. Tabit CE, Chung WB, Hamburg NM and Vita JA: Endothelial dysfunction in diabetes mellitus: Molecular mechanisms and clinical implications. Rev Endocr Metab Disord 11: 61-74, 2010.

22. Hill JM, Zalos G, Halcox JP, Schenke WH, Waclawiw MA, Quyyumi AA and Finkel T: Circulating endothelial progenitor cells, vascular function, and cardiovascular risk. N Engl J Med 348: 593-600, 2003.

23. Rafii S and Lyden D: Therapeutic stem and progenitor cell transplantation for organ vascularization and regeneration. Nat Med 9: 702-712,2003.

24. Asahara T, Murohara T, Sullivan A, Silver M, van der Zee R, Li T, Witzenbichler B, Schatteman G and Isner JM: Isolation of putative progenitor endothelial cells for angiogenesis. Science 275: 964-967, 1997.
25. Vasa M, Fichtlscherer S, Aicher A, Adler K, Urbich C, Martin H, Zeiher AM and Dimmeler S: Number and migratory activity of circulating endothelial progenitor cells inversely correlate with risk factors for coronary artery disease. Circ Res 89: E1-E7, 2001.

26. Landmesser U, Engberding N, Bahlmann FH, Schaefer A, Wiencke A, Heineke A, Spiekermann S, Hilfiker-Kleiner D, Templin C, Kotlarz D, et al: Statin-induced improvement of endothelial progenitor cell mobilization, myocardial neovascularization, left ventricular function, and survival after experimental myocardial infarction requires endothelial nitric oxide synthase. Circulation 110: 1933-1939, 2004.

27. Klein JJ, Goldstein AL and White A: Enhancement of in vivo incorporation of labeled precursors into DNA and Total protein of mouse lymph nodes after administration of thymic extracts. Proc Natl Acad Sci USA 53: 812-817, 1965.

28. Rossdeutsch A, Smart N, Dube KN, Turner M and Riley PR: Essential role for thymosin beta4 in regulating vascular smooth muscle cell development and vessel wall stability. Circ Res 111: e89-e102, 2012.

29. Kaur H, Mutus B. Platelet function and thymosin beta 4. Biol Chem 393: 595-598, 2012

30. Malinda KM, Sidhu GS, Mani H, Banaudha K, Maheshwari RK, Goldstein AL and Kleinman HK: Thymosin beta 4 accelerates wound healing. J Invest Dermatol 113: 364-368, 1999.

31. Lv S, Cheng G, Zhou Y and Xu G: Thymosin beta4 induces angiogenesis through Notch signaling in endothelial cells. Mol Cell Biochem 381: 283-290, 2013.

32. Wang L, Chopp M, Szalad A, Liu Z, Lu M, Zhang L, Zhang J, Zhang RL, Morris D and Zhang ZG: Thymosin beta4 promotes the recovery of peripheral neuropathy in type II diabetic mice. Neurobiol Dis 48: 546-555, 2012.

33. Kim S and Kwon J: Effect of thymosin beta 4 in the presence of up-regulation of the insulin-like growth factor-1 signaling pathway on high-glucose-exposed vascular endothelial cells. Mol Cell Endocrinol 401: 238-247, 2015.

34. Everaert BR, Van Craenenbroeck EM, Hoymans VY, Haine SE, Van Nassauw L, Conraads VM, Timmermans JP and Vrints CJ: Current perspective of pathophysiological and interventional effects on endothelial progenitor cell biology: Focus on PI3K/AKT/eNOS pathway. Int J Cardiol 144: 350-366, 2010.

35. Dimmeler S, Aicher A, Vasa M, Mildner-Rihm C, Adler K, Tiemann M, Rütten H, Fichtlscherer S, Martin H and Zeiher AM: HMG-CoA reductase inhibitors (statins) increase endothelial progenitor cells via the PI 3-kinase/Akt pathway. J Clin Invest 108: 391-397, 2001

36. Fulton D, Gratton JP, McCabe TJ, Fontana J, Fujio Y, Walsh K, Franke TF, Papapetropoulos A and Sessa WC: Regulation of endothelium-derived nitric oxide production by the protein kinase Akt. Nature 399: 597-601, 1999.

37. Aicher A, Heeschen C, Mildner-Rihm C, Urbich C, Ihling C, Technau-Ihling K, Zeiher AM and Dimmeler S: Essential role of endothelial nitric oxide synthase for mobilization of stem and progenitor cells. Nat Med 9: 1370-1376, 2003.

38. Sun N, Wang $\mathrm{H}$ and Wang L: Vaspin alleviates dysfunction of endothelial progenitor cells induced by high glucose via pi3k/Akt/eNOS pathway. Int J Clin Exp Pathol 8: 482-489, 2015.

This work is licensed under a Creative Commons Attribution-NonCommercial-NoDerivatives 4.0 International (CC BY-NC-ND 4.0) License. 